\title{
Rethinking presence: A grounded theory of nurses and teleconsultation
}

\author{
David Barrett \\ Faculty of Health and Social Care, University of Hull
}

Word count: 5409 (Excluding abstract, summary box and reference list)

\begin{abstract}
Aims and objectives

The study aimed to develop a theory that offered an evidence-based insight into the use of teleconsultation by nurses.
\end{abstract}

\section{Background}

Teleconsultation is the use of video to facilitate real-time, remote interaction between healthcare practitioners and patients. Though its popularity is growing, there is little understanding of how teleconsultation impacts on the role of nurses.

\section{Method}

The study adopted a constructivist grounded theory method, supplemented by the use of Straussian analytical approaches. Using selective and theoretical approaches, Registered Nurses with experience of using video in healthcare were sampled. Data were collected using semi-structured interviews exploring experiences, knowledge and feelings surrounding teleconsultation. Interviews were recorded, transcribed and subjected to three-stage, non-linear manual analysis (open, axial and selective coding).

\section{Results}

Theoretical saturation occurred after 17 interviews. The core category identified from the data was 'nursing presence' Four subcategories of nursing presence were identified: Operational, clinical, technical and social. The degree to which presence could be achieved was dependent upon three influencing factors - enablers, constraints and compensation.

This is the peer reviewed version of the following article: Barrett, D. (2017), Rethinking presence: a grounded theory of nurses and teleconsultation. J Clin Nurs, 26: 3088-3098, which has been published in final form at http://dx.doi.org/10.1111/jocn.13656]. This article may be used for non-commercial purposes in accordance With Wiley Terms and Conditions for self-archiving. 


\section{Conclusion}

Nurses provide different types of presence during teleconsultation, with the degree of presence dependent on specific characteristics of video-mediated communication. Where the use of video constrains the delivery of presence, nurses utilise a range of compensatory mechanisms to enhance patient care.

\section{Relevance to clinical practice}

Teleconsultation provides an innovative approach to enhancing the delivery of healthcare. This study provides nurses with insight into the impact of teleconsultation on their professional role, and an understanding of how best to use video-mediated communication to support patient care.

\section{Keywords}

Telenursing, technology, information technology, communication, grounded theory 


\section{SUMMARY BOX}

\section{'What does this paper contribute to the wider global clinical community?'}

- This study provides insight into the different uses of teleconsultation (use of video to support patient care) by nurses

- Nurses are able to provide different types of 'nursing presence' - operational, clinical, therapeutic and social - via teleconsultation

- The degree of presence delivered is subject to medium-specific influencing factors

\section{INTRODUCTION}

Commissioners, providers and purchasers of health and social care face a number of complex and developing challenges. An ageing population, increased prevalence of long-term conditions (LTCs), clinical complexity and public spending austerity are some examples of the specific pressures felt across the globe (Barrett et al., 2015). As a result, policy-makers, care organisations and individual clinicians are seeking solutions that allow for more effective use of resources, facilitate an independent, self-caring population and reduce the demand on acute and secondary care services. In response to these challenges, commissioners and providers have explored and piloted a range of innovative approaches to service delivery, including those that involve the utilisation of information technologies (While \& Dewsbury, 2011).

One such modality of care is teleconsultation - defined for the purposes of this study as the utilisation of video to facilitate real-time, remote consultation between healthcare practitioners and patients. Though teleconsultation has been used as an approach to care since the 1970s (Freiburger et al., 2007), it has grown in prevalence of late, due to improved connectivity and greater social acceptance of video-mediated interaction. Applications such as Skype and FaceTime have also removed the need for bespoke videoconferencing hardware and opened 
the door for low-cost teleconsultation services in a range of clinical areas (Armfield et al., 2012).

The study aimed to explore the use of teleconsultation by nurses, with the specific objective of developing a theory that provides a framework for understanding nurses' use of video-mediated interaction. The specific research question answered by the study was 'how do nurses use teleconsultation?'

\section{BACKGROUND}

Teleconsultation is used to address three broad challenges to the delivery of care: geographical barriers, logistical barriers and lack of specialist support. Geographical barriers, such as distance and/or bodies of water, can be overcome through the use of video-mediated remote interaction (Audit Scotland, 2011); complex patient transfer, which cause substantial logistical challenges, can be reduced through innovations such as teleconsultations with prisoners who have healthcare problems (Cruikshank \& Paxman, 2013); specialist support, such as that required to support acute stroke assessment and treatment, can also be provided remotely via video (Demaerschalk et al., 2012). Clinically, teleconsultation is utilised in areas such as dermatology (Warshaw et al., 2011), end-of-life care (Low et al., 2013) and critical care (Goran, 2010).

As teleconsultation services have continued to grow and diversify, nurses have been at the forefront. The central role of nurses in these developments is not surprising: consultation, interaction and discussion with patients has traditionally been the cornerstone of nursing practice (Shattell, 2004). Where the medium through which these interactions is altered (for example, a shift from face-to-face to video-mediated communication), nurses will tend to be the professional group affected to the largest degree. 
Despite increasing use of teleconsultation in practice, there is not yet a complete understanding of how these approaches to care impact on nursing roles, professional status and relationships with patients. It is not clear exactly what the impact of technology is on a nurse's ability to know, interact with and care for their patients (Nagel et al., 2013). Without this understanding, it is not possible to have a true insight into how best to support the further development and delivery of teleconsultation services by nurses. This study aimed to provide a better understanding of what teleconsultation means for nurses and their profession.

\section{METHOD}

The work adopted a Constructivist Grounded Theory (GT) approach. GT requires the development of theory from data, rather than (as is the case in many research methods) using data to test theory (Strauss \& Corbin, 1998). Under the broad umbrella of grounded theory sit a number of different 'schools' - notably Glaserian, Straussian and Constructivist. Though the fundamental philosophy of GT - that theory is generated from data - is present in each of these schools, each has different views on analytical processes, the nature of findings and the role of the researcher. Constructivist GT, outlined by Charmaz (2000) is underpinned by the broad belief that the researcher cannot be viewed as separate from the emerging findings.

Charmaz (2000) approaches grounded theory from an interpretive perspective and integrates the previous work of symbolic interactionists into her writing. The role of the researcher is not simply to collect data, identify emerging themes and generate theory. Instead, the researcher works with participants to construct a reality that is shaped by those it includes. Taking this view of the world, realities that are constructed during the course of a study will be as numerous as there are participants. Elements of these realities will be common across participants, but each is unique and dependent on context (Mills et al., 2006). The theories that result from this method are not static entities waiting to be discovered; they are flexible, dynamic and subjective constructs based upon the interactions and perspectives of participants, researcher 
and existing knowledge (Charmaz, 2006). Charmaz recognised that researchers will bring their own experiences and knowledge into any field of study. Indeed, the construction of a grounded theory is dependent on the input of the researcher, interacting with participants to identify a contextually valid reality.

Though there are substantial differences between the schools of GT, they do not need to be compartmentalised and placed into their own epistemological silos. In reality, the different approaches all have their place on continuum (Charmaz, 2000) or 'methodological spiral' (Mills et al, 2006), allowing researchers to select elements of each depending on the characteristics of their study. This study took a constructivist GT approach, but supplemented it with some specific Straussian analytical approaches (Strauss \& Corbin, 1998).

The study adopted a three-stage sampling approach. Firstly, a pool of potential participants was recruited - these were Registered Nurses (RNs) with experience of using teleconsultation, who expressed an interest in being part of the study. Secondly, five RNs from this pool were sampled selectively. Draucker et al. (2007) explored the use of 'selective sampling', in which populations and settings are identified ahead of any data collection during the early stages of GT studies. The five RNs selected at this stage had used teleconsultation in different ways and different settings, thereby providing a range of experiences.

Once data collection and analysis from the first tranche of participants had commenced, concepts began to emerge and a move was made from selective sampling to a theoretical sampling technique (Draucker et al., 2007). Sampling decisions were made on the basis of emerging themes and specific areas of enquiry - a defining characteristic of theoretical sampling specifically and of grounded theory generally (Charmaz, 2006). Sampling continued until new participants were no longer able to yield fresh data that "...sparks new theoretical 
insights..." (Charmaz, 2006:113). At this point, theoretical saturation was judged to have occurred and data collection ceased (Higginbottom, 2004).

Data were collected using semi-structured interviews exploring RNs' experiences, knowledge and feelings surrounding teleconsultation. To supplement interview data, memo-writing (in the form of 'field notes', diagrams and charts) were used to shape thoughts about the data and reflect on findings (Lempert, 2007). Ethical approval for this approach was granted by the Faculty of Health and Social Care Research Ethics Committee at the University of Hull.

Interviews were recorded and transcribed. Participants were given a unique identifier (TCXX) to allow for anonymous linkage to specific quotes. Data were analysed manually, using open, axial and selective coding. The first formal stage of analysis - open coding - involved a 'microanalysis' (word-by-word; line-by-line; phrase-by-phrase; sentence-by-sentence) of the transcribed interviews and accompanying memos/field notes (Strauss \& Corbin, 1998). As open codes were developed, the relationships between them were identified through a process of constant comparative analysis: contrasting data against itself, new data, and established theory to facilitate the emergence of new ideas (Boychuk Duchscher \& Morgan, 2004). This method of qualitative analysis is a fundamental characteristic of GT studies and remains an important foundation upon which theories can emerge (Mills et al., 2006). By using a range of analytical techniques, constantly comparing codes, revisiting previous data, recognising similarities, conflicts and contradictions, it was possible to take disparate codes and identify from them a more coherent series of categories. During this early phase of coding, previous literature was also revisited and existing knowledge was reflected upon to enhance sensitivity to emerging categories.

Next, axial coding was undertaken to make connections and identify relationships between categories and their subcategories (Strauss \& Corbin, 1998). Whereas open coding requires 
breaking down the raw data, axial coding involves putting it back together again in different ways (Kendall, 1999). Finally, selective coding took place. This final stage of analysis outlined by Strauss and Corbin (1998) describes a process through which categories are further refined and integrated to develop, in this case, a theory related to the use of teleconsultation by nurses. A crucial stage of this process was the identification of a core or central category. This central category needed to relate to all other categories within the theory, be explicit within much of the data, abstract enough to allow for related research to take place, and flexible enough to accommodate contradictory or alternative interpretations of teleconsultation use (Strauss \& Corbin, 1998). Constant comparative analysis, supported by the use of memos and diagrams, allowed a core category to be identified that encompassed the main theme of the emerging grounded theory and which had a clearly defined relationship to all other categories.

\section{RESULTS}

Theoretical saturation occurred after 17 interviews. Participants had varying experience, worked within a range of clinical contexts and used teleconsultation in different ways (table 1). Two broad categories of teleconsultation were identified: Nurse-Patient (N-P) teleconsultations, in which the $\mathrm{RN}$ and patient were remote from each and interacted via video, and Nurse/Patient-Practitioner (NP-Pr) teleconsultations, in which the RN and the patient were physically proximal, while another practitioner (usually a doctor) joined the triad via a videolink.

\begin{tabular}{|c|c|l|l|}
\hline Number & Role & Teleconsultation experience & Clinical area \\
\hline TC01 & Nurse manager & $\begin{array}{l}\text { Management oversight and } \\
\text { clinical involvement with N-P } \\
\text { teleconsultation }\end{array}$ & Acute care \\
\hline TC02 & $\begin{array}{c}\text { Teleconsultation } \\
\text { nurse }\end{array}$ & $\begin{array}{l}\text { Specialist clinical role involving } \\
\text { N-P teleconsultation }\end{array}$ & Acute care \\
\hline TC03 & $\begin{array}{c}\text { Clinical nurse } \\
\text { specialist }\end{array}$ & $\begin{array}{l}\text { Managerial and clinical role } \\
\text { related to N-P teleconsultation }\end{array}$ & Burns care \\
\hline
\end{tabular}




\begin{tabular}{|c|c|c|c|}
\hline TC04 & Staff Nurse & $\begin{array}{l}\text { Clinical experience as proximal } \\
\text { nurse within NP-PR } \\
\text { teleconsultation }\end{array}$ & $\begin{array}{l}\text { Emergency } \\
\text { department }\end{array}$ \\
\hline TC05 & Charge Nurse & $\begin{array}{l}\text { Clinical experience as proximal } \\
\text { nurse during NP-Pr } \\
\text { teleconsultation }\end{array}$ & Renal medicine \\
\hline TC06 & $\begin{array}{l}\text { Clinical Nurse } \\
\text { Specialist }\end{array}$ & $\begin{array}{l}\text { Runs clinics through N-P } \\
\text { teleconsultation }\end{array}$ & Diabetes \\
\hline TC07 & $\begin{array}{l}\text { Clinical Nurse } \\
\text { Specialist }\end{array}$ & $\begin{array}{l}\text { Clinical experience of NP-Pr } \\
\text { teleconsultation }\end{array}$ & Oncology \\
\hline TC08 & Staff Nurse & $\begin{array}{l}\text { Some experience of education } \\
\text { via teleconsultation. }\end{array}$ & Gastroenterology \\
\hline TC09 & $\begin{array}{l}\text { Clinical Nurse } \\
\text { Specialist }\end{array}$ & $\begin{array}{l}\text { Clinical involvement as } \\
\text { proximal nurse during NP-Pr } \\
\text { teleconsultation }\end{array}$ & Oncology \\
\hline $\mathrm{TC} 10$ & Charge Nurse & $\begin{array}{l}\text { Clinical involvement as } \\
\text { proximal nurse during NP-Pr } \\
\text { teleconsultation }\end{array}$ & Stroke care \\
\hline $\mathrm{TC} 11$ & $\begin{array}{l}\text { Teleconsultation } \\
\text { nurse }\end{array}$ & $\begin{array}{l}\text { Specialist clinical role involving } \\
\text { N-P teleconsultation }\end{array}$ & Acute care \\
\hline $\mathrm{TC} 12$ & $\begin{array}{l}\text { Teleconsultation } \\
\text { nurse }\end{array}$ & $\begin{array}{l}\text { Specialist clinical role involving } \\
\text { N-P teleconsultation }\end{array}$ & Acute care \\
\hline TC13 & $\begin{array}{l}\text { Project support } \\
\text { nurse }\end{array}$ & $\begin{array}{l}\text { Project management and clinical } \\
\text { experience with N-P } \\
\text { teleconsultation }\end{array}$ & Acute care \\
\hline $\mathrm{TC} 14$ & Staff Nurse & $\begin{array}{l}\text { Clinical involvement as } \\
\text { proximal nurse during NP-Pr } \\
\text { teleconsultation }\end{array}$ & Stroke care \\
\hline $\mathrm{TC} 15$ & $\begin{array}{l}\text { Clinical Nurse } \\
\text { Specialist }\end{array}$ & $\begin{array}{l}\text { Clinical involvement as } \\
\text { proximal nurse during NP-Pr } \\
\text { teleconsultation }\end{array}$ & Stroke care \\
\hline $\mathrm{TC} 16$ & $\begin{array}{l}\text { Clinical Nurse } \\
\text { Specialist }\end{array}$ & $\begin{array}{l}\text { Runs clinics through N-P } \\
\text { teleconsultation }\end{array}$ & Diabetes \\
\hline $\mathrm{TC} 17$ & $\begin{array}{l}\text { Senior critical } \\
\text { care nurse }\end{array}$ & $\begin{array}{l}\text { Implemented teleconsultation in } \\
\text { intensive care setting }\end{array}$ & Critical care \\
\hline
\end{tabular}

\section{Table 1: Characteristics of participants}

Analysis of the interview data identified that nurses carried out a variety of roles and functions during teleconsultation, focused upon the concept of 'being there' for patients - this was the case in both N-P and NP-Pr teleconsultations. The term 'presence' was identified as the best descriptor to connect the different elements of the nursing role in teleconsultation: nurses reported being present in teleconsultation (or, in some cases, not being present) for different 
reasons and in different ways. Four interlinked subcategories of presence were identified from the data that encompassed nursing in its totality: operational presence, clinical presence, therapeutic presence and social presence. These were, in turn, all linked to a core category identified as nursing presence (figure 1)

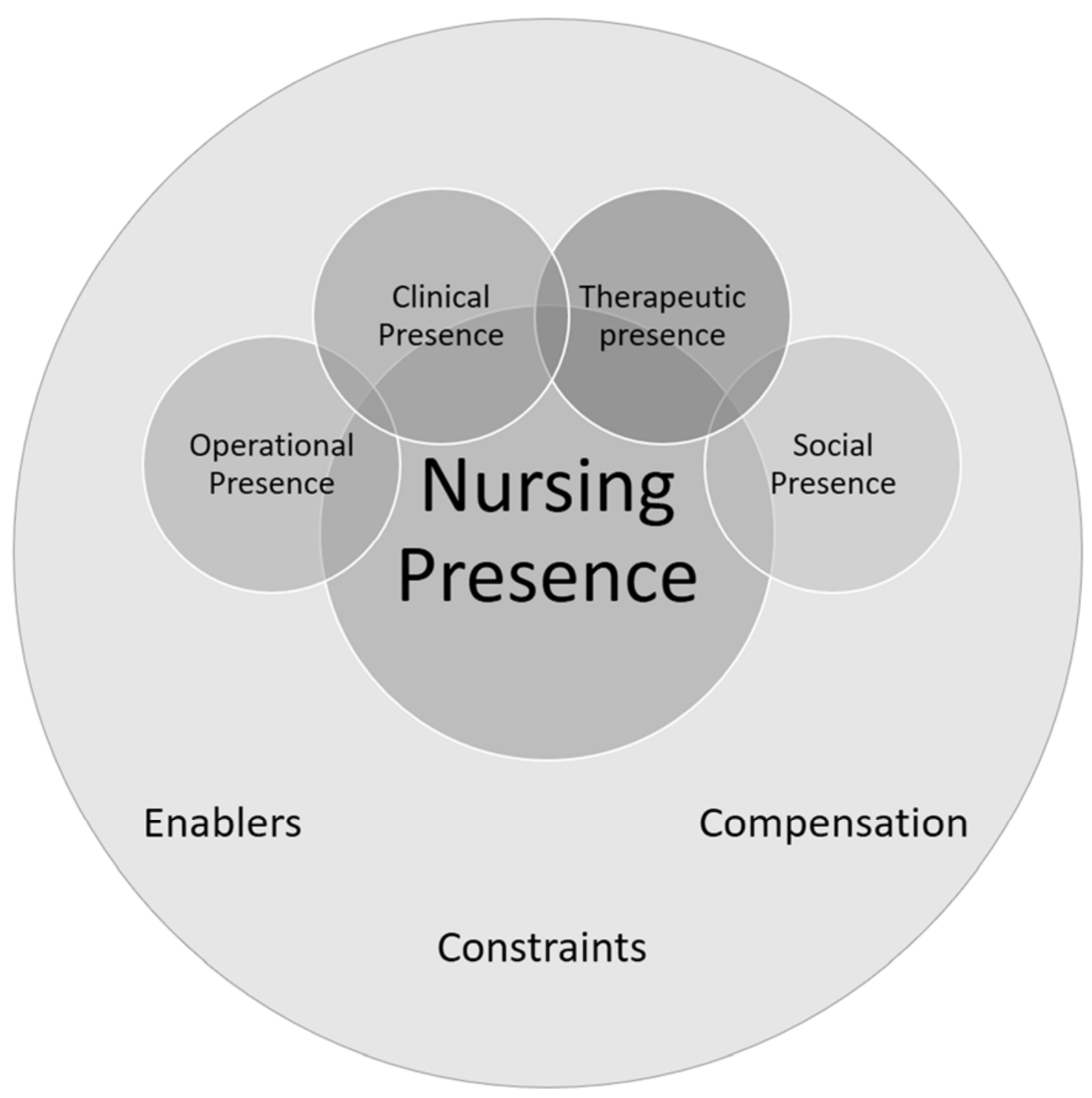

Figure 1: Grounded theory of nurses and teleconsultation

Operational presence: This subcategory encompassed the operational and organisational role played by the nurse during a teleconsultation. On occasions, the operational role of the nurse was summarised as the 'headline' purpose for the nurse being there. For example, some nurses 
were required to be available to answer a video-mediated call from a patient or to facilitate a remote outpatient clinic.

“...my role is really more facilitating the video clinics...being there to make sure everything works okay...” (Participant TC09)

Other examples of operational roles were more specific, though still related to the facilitation of organisational functions. Nurses described leading or taking part in administrative functions such as organising patient flow through a teleconsultation clinic or ensuring the involvement of all necessary members of the multidisciplinary team:

"...you have to put out the stroke call, which goes to the med reg and to CT [computed tomography]...we contact the consultant while the patient is being CT'd.” (TC10)

One element of an RN's operational role unique to technology-mediated care services such as teleconsultation appeared to be provision of technical support for the interaction. These roles included setting up the teleconsultation equipment at one end of the interaction, directing the use of technology by patients or practitioners at the other end of a consultation, or providing a troubleshooting service:

"So we get the whole bed space ready-get ready for them. We'll put the telemedicine machine next to the bed, switch it on. That's all literally we have to do - switch the machine on, the link is then established." (TC15)

Clinical presence: Each description of a teleconsultation referred to there being one or more key clinical functions carried out by the nurse. These functions were related to the overall purpose of the nurse participating in an interaction with a patient, so had links to their operational role. However, whereas operational roles were more service-focused, clinical roles encompassed a number of specific tasks, objectives and activities associated with direct, 
patient-focused care. For example, some nurses were required to facilitate a remote outpatient clinic for patients (operational presence), involving a series of patient-focused tasks such as history-taking, visual examination, provision of advice and prescription of care (clinical presence).

“...you're still seeing the patient, devising a plan, evaluating - you know, you're still doing the nursing process with them...” (TC13)

One of the strongest areas of the clinical role to emerge from the data was patient assessment. This was carried out remotely (in the case of N-P teleconsultation), or whilst being proximal to the patient (in NP-Pr interactions). For example, one nurse offered a brief insight into assessing her patients via video, gathering information from both the patient and their proximal carer:

"I get a history from the carer. I ask to then see the patient...and basically ask the patient if they're able to answer how they feel.” (TC12)

In the case of NP-Pr teleconsultation, the assessment role was described as being carried out by the $\mathrm{RN}$, on behalf of the remote practitioner.

“They will ask you to double-check things and 'can you get them to do that?'” (TC15)

Therapeutic presence: Participants described elements of their role within teleconsultation that supported the patient and/or carer, but were peripheral to the specific object and function of the consultation. For example, nurses describing their delivery of clinics via teleconsultation outlined their role in relation to operational presence (to provide a follow-up clinic) and clinical presence (history-taking, visual examination, treatment and planning). However, interactions that took place during the teleconsultation also provided a broader therapeutic purpose beyond 
the primary reason for the consultation, including provision of reassurance and support, and development of the nurse-patient relationship.

During N-P teleconsultations, these therapeutic roles could involve interventions such as recognising and responding to non-verbal cues that might signify important patient issues. Though this was an extension of the primary assessment process, it also suggested a broader, more holistic approach to care:

“...if we have a worry and you think 'oh, they are perhaps not as clean as they were a few days before...or they are not able to brush their hair...those kinds of issues are really valuable." (TC01)

Other participants with experience of N-P teleconsultation described their interventions as offering comfort and reassurance to patients:

“...they're pleased to see you, often quite reassured, they like to hear your voice, see your expressions. It's a comfort as well as a reassurance a lot of the time.” (TC07)

In NP-Pr teleconsultation, the proximal RN, in addition to their clinical functions, also carried out some more nebulous but nonetheless extremely valuable roles:

"So it's kind of supporting the patient...we can kind of have a chat afterwards just about how they feel." (TC09)

Social presence: Aside from the operational, clinical and therapeutic elements of their role, participants also highlighted the importance of someone 'being' with the patient or with other practitioners during a teleconsultation. This aspect of the role related not directly to any particular therapeutic aim or objective, but just to the social interaction that takes place during healthcare interventions. 
“...I just do my best to, you know, chat and I'll say 'oh, I like your curtains' or, you know, the usual stuff you do as a nurse. Icebreaking to make sure that, you know, they're comfortable and they can speak to you..." (TC13)

“We'll have quite a lot of them all saying 'I can't see what you're wearing today - first of all, stand up and give us a twirl!'” (TC06)

In addition, in the context of N-P teleconsultation, participants described attempting to enhance social presence by reducing the visibility of the technological medium and giving the patient the sense that they are 'in the room' with them.

"When you do a teleconference it is like being in the room with somebody and whoever is in that room is involved...” (TC04)

\section{Enablers, constraints and compensation}

The subcategories of nursing presence were influenced by three contextual factors that emerged from the data: enablers, constraints and compensation. These influencing factors acted upon the ability of nurses to be 'present' during teleconsultation, and the extent to which different subcategories of presence could be achieved.

Enablers were those characteristics of teleconsultation that enhance the degree of presence that can be achieved. The main enabler identified during the study was the added value of sight that teleconsultation provided (when compared to the telephone) during interactions.

“... [the video] allows you to get properly involved.” (TC07)

“... [patients] like seeing a face. They do like seeing a face...there's definitely some link with what I feel is a difference in the quality of the consultation and that interface with your patient if you can see them." (TC11) 
Conversely, there were a number of elements of teleconsultation that limited the degree of presence that nurses can offer. For example, whilst the visual link provided by the video could enhance nursing presence, limitations associated with the technology, such as technical failure, could inhibit it:

"You've got a slight time lapse, which some people find is difficult to get the hang of." (TC09)

“Sometimes there’s equipment failures and obviously that's a big let-down.” (TC04)

In addition to impacting on the degree of presence within individual consultations, technical failure also provided a barrier to broader uptake and adoption of teleconsultation by nurses. One respondent described those nurses who...

“...will find problems and faults with things...I think those early niggles were things like occasional sound drop out and picture pixilation. In the early days it was 'oh, this is hopeless - can't use this." "' (TC05)

One of the defining characteristics of carrying out a consultation via video is that the two 'ends' of the interaction are unable to have any physical contact with each other. From a nursing perspective, this was most keenly felt when the nurse was remote from the patient (i.e. during N-P teleconsultations). Participants described this constraint both in relation to the direct effect that lack of touch had on their clinical presence, and the impact on broader, more therapeutic, elements of the nursing role:

"I think that the most difficult part of it initially was not being able to physically touch the person that you were speaking to, which is a huge thing....to touch them, to reassure them, to feel their pulse, to feel their skin. All your visual assessments that that you do as a nurse, we do have that video link, but that touch element of that isn't there.” (TC02) 
The final influencing factor to emerge from the data was compensation - strategies put in place by nursing staff or others to mitigate the constraints of teleconsultation and optimise the degree of presence delivered. Examples included education for staff, patient and carers, and the enhanced frequency of interaction facilitated by teleconsultation.

The use of the physically proximal 'third party' was the most commonly cited compensatory mechanism. In the case of an N-P teleconsultation, the third party might be another practitioner who was located physically with the patient...

“To find out how deep a burn is, you press on it...you can't do that [with teleconsultation], but you can get someone over there to press on it. So, you can get the camera to focus in and say 'right, press on that bit there, press on that bit here'." (TC03)

...whereas nurses who were proximal to the patient during NP-Pr teleconsultation were themselves used as the third party:

“...a lot of them do it through the nurse. 'Can you get the patient to do this?' 'Can you get missus so-and-so to move that arm?"” (TC10)

The data also suggested that there were occasions where compensatory mechanisms could not overcome the constraints associated with teleconsultation and that sufficient nursing presence could not be achieved. In these cases, the approach of participants was to exclude certain groups or situations from the use of teleconsultation overall:

“You would never see a new patient, a completely new patient [via teleconsultation].” (TC09) “...if it is someone who is old or has significant mental health problems and we think that telemedicine might be too difficult for them...they can still be offered a face-to-face appointment.” (TC06) 
Overall, the data from interviews and memos suggest that during teleconsultation, nurses consistently demonstrate four types of presence. However, the balance between the four subcategories of presence, and the degree to which they are demonstrated, varies according to medium-specific influencing factors.

\section{DISCUSSION}

The development of a core category of nursing presence, encompassing four subcategories, emerged from analysis of the data related to teleconsultation and nursing, as is the requirement of any grounded theory (Strauss \& Corbin, 1998). However, 'nursing presence' itself is not a new concept: it has been identified previously as a phenomenon that occurs at specific points in time as part of the nurse-patient (Doona et al, 1999).

In previous conceptualisations of presence, authors have tended to include some element of physical presence that incorporates behaviours such as touch, non-verbal communication and maintaining close proximity (Easter, 2000; Zyblock, 2010). The issue of proximity is obviously a key one in the context of teleconsultation, where agents are often remote from one another. Previously published theoretical positions on remoteness and nursing presence are equivocal. Though Finfgeld-Connett (2008) described the importance of 'intimate interpersonal sensitivity' as an attribute associated with nursing presence, she makes no explicit reference to a need for physical closeness between nurse and patient. Conversely, Zyblock (2010) was adamant that physical proximity is vital for a nurse to be present, whilst Easter (2000) required actual closeness for one 'mode' of presence in her model (namely physical presence).

Given the suggested importance of physical proximity, it is surprising that there has been little previous research or discussion related to nursing presence in the context of technologymediated healthcare. In one rare example, Tuxbury (2013) sought to identify examples of nursing presence during remote monitoring of, and telephone interactions with, patients. 
Though focusing on the use of technology to support care, Tuxbury (2013:156) adopted a traditional viewpoint of nursing presence, defining it as "a reciprocal flow of openness in the dialogue." Speaking to six nurses who had used the telephone to interact with remotely monitored patients, Tuxbury (2013) identified only two occurrences of nursing presence, where she described the interaction as reaching total openness.

The work of Tuxbury (2013) demonstrated one of the fundamental differences between traditional theories of nursing presence and those postulated within this grounded theory. In the past, nursing presence has been described as something that can occur infrequently and only in certain circumstances - nurses can be literally present without offering 'presence'. In this grounded theory of teleconsultation, the emerging data suggested that when involved with patient care, nurses were always present in one way or another and to one extent or another. The participants' discussion of their role suggested that they had some degree of operational, clinical, therapeutic or social presence at all times when interacting with, or on behalf of, patients.

The grounded theory also identified a number of enablers, constraints and compensatory mechanisms associated with the use of teleconsultation by nurses. Of the enablers identified, the strongest theme to emerge was the value of seeing the patient, in comparison to the audioonly character of telephone consultations. Previous teleconsultation projects involving nurses have highlighted how the visual cues provided by video, even when of a relatively low fidelity, can provide nurses with important information regarding the clinical status of patients. Jenkins and White (2001) described how nurses could gather assessment data from patients with heart failure via a small (3-inch) video screen. Despite the technological limitations, nurses reported being able to assess a range of clinical features, such as ankle oedema, wounds or abnormalities in gait. 
The ability to see the patient during teleconsultation allows for nonverbal communication to take place. Cues such as patient directed gaze, affirmative head nodding and smiling - all elements which could be utilised during video-mediated communication (but not via the telephone) - are thought to influence the capability of nurses to develop therapeutic relationships and optimise the outcomes of nurse-patient interactions (Caris-Verhallen et al., 1999).

Eye contact was also highlighted by participants as an enabler of presence facilitated by the use of video. Eye contact during interactions is an important element of patient centred communication and can enhance the level of trust that a patient has in a healthcare practitioner (Gorawara-Bhat \& Cook, 2011; Bohannon et al., 2013). Coupled to this, the use of video to mediate interactions can allow for the demonstration of emotion via facial expressions, thereby providing another layer of information to enhance communication (Schmidt et al., 2011).

The greatest barrier providing nursing presence during teleconsultation was identified as the inability to touch the patient. One of the defining characteristics of carrying out a consultation via video is that the two 'ends' of the interaction are unable to have any physical contact with each other. From a nursing perspective, this was most keenly felt when the nurse was remote from the patient (i.e. during N-P teleconsultations). Participants described this constraint both in relation to the direct effect that lack of touch had on their clinical presence, and the impact on broader, more therapeutic, elements of the nursing role. Whereas an inability to touch might be considered a constraint for any healthcare professional involved in teleconsultation, it is arguably of particular relevance in nursing practice, where touch is sometimes considered to be an inherent part of the role. There is a plethora of research, opinion and reviews in the nursing literature, highlighting the importance of touch as a prerequisite to high quality care. For some authors, the place of touch as a central tenet of nursing care is unquestionable. Chang 
(2001: 820), for example, claimed that “...it has been accepted that physical touch is an essential and universal component of nursing care..."

There is no doubt that touch is something that takes place in very many nurse-patient interactions, that touch can be a powerful facilitator of nurse-patient communication and that there is good quality evidence that touch, when used appropriately by nurses, can offer benefits to patients in a variety of clinical settings (Coakley \& Duffy; 2010; Karagozoglu \& Kahve, 2013; Lindgren et al., 2013). It could therefore be hypothesised that if a nurse is remote from their patient and only able to communicate through the medium of video, an inability to touch will preclude them from offering high-quality care. However, the grounded theory of teleconsultation outlined here suggests that this is not the case. Though the data suggest that lack of touch is indeed a constraint to presence, it is neither an insurmountable one, nor one that detracts from the essence of nursing care - nurses involved in teleconsultation are still caring, just in a different way.

To overcome issues such as the lack of touch, participants described a range of compensatory mechanisms that they utilised. The use of the third party was most commonly described approach to overcoming limitations - these parties, who were proximal to the patient - could act as a 'pair of hands', providing additional information to patients and offering technical support where required. Ferguson (2006) described the role of a proximal practitioner carrying out tasks on behalf of their remote, more specialist colleague during teleconsultations. Esterle and Mathieu-Fritz (2013), in an observational study of approximately 100 teleconsultations between specialist consultants, geriatricians and patients, highlighted the importance of physical examination being delegated to a proximal practitioner. LeRouge et al. (2012:629) outlined a similar role for proximal practitioners in a range of telemedicine (teleconsultation) services, describing them as "...a conduit of the doctor's arms and eyes..." Some of the participants in the current study who described their role as the third party were involved in 
stroke care, an area where the need for proximal practitioners to carry out assessments on behalf of the remote specialist has also been described elsewhere (Hervieu-Begue et al., 2013). Shah et al. (2013) outlined the function of a practitioner within their teleconsultation service - the Certified Telemedicine Assistant - that demonstrated the importance of the proximal third party through formalisation of the role.

The role of the nurse as intermediary was also described by Tachakra and Rajani (2002) in the context of teleconsultations to support emergency care. During these NP-Pr interactions, nurses were not only asked to perform physical and technical tasks in their role as third party, but they also acted as an important channel of communication. In some instances, this was to compensate for technical issues (for example, poor audio may have made it difficult for patients to hear questions), whilst in others, the nurse-as-third-party was used to 'translate' medical terminology for the benefit of the patient. One of the conclusions reached by Tachakra and Rajani (2002) was that the interactions between the nurse and patient at one end of the teleconsultation had a large bearing on its success. Work by Sävenstedt et al. (2005), exploring the role of Enrolled Nurses (ENs) who were proximal to care home residents whilst having teleconsultations with an $\mathrm{RN}$, identified the importance of the proximal third party acting as an intermediary between the $\mathrm{RN}$ and the resident, providing additional explanation or translating instructions and requests. These previous studies mirror the findings of this current work, by recognising that acting as a third party during video-mediated communication is an important and complex nursing role.

The study has a number of limitations. The use of grounded theory as a method brings with it inherent limitations: the approach is dependent on the development of theory based on data from a relatively small and narrowly defined group. As such, the generalizability of the study to broader populations is questionable (Egan, 2002), though the detailed discussion of methods and use of primary data has enhanced the transferability and trustworthiness of findings 
(Graneheim \& Lundman, 2004). Nonetheless, further work is therefore required to explore the validity of the grounded theory. In addition, the key methodological elements of the work design, sampling, interviewing and analysis - were carried out by a single researcher. Other than doctoral supervision, there was no external oversight or review of emerging themes, potentially increasing the risk of bias.

\section{CONCLUSION}

This study has generated a nascent theory that proposes different types of presence demonstrated by nurses during teleconsultation. It is hypothesised that the degree of presence will depend on specific characteristics of video-mediated communication and strategies employed by nurses to optimise the quality and value of the interaction. This outline theory of presence requires further study. In particular, validation work is required in different areas of technology-mediated nursing care (e.g. telephone triage), to explore whether the same framework can be applied, albeit subject to different contextual factors. Study of the framework within more traditional areas of nursing practice is also required, to explore whether the grounded theory of teleconsultation is a valid tool for reconceptualising the general role of the nurse.

Further study is also required on the interrelatedness and interconnectedness of different subcategories of nursing presence. It is known that conflict can arise between an expectation of nursing being based around provision of holistic care and a reality of the role being multiskilled and often focused on delivering organisational objectives (Allen, 2004). Based upon this, work is required to ascertain whether similar role tensions exist between the four proposed subcategories of nursing presence, and - if so - explore how they are managed by nurses. Greater understanding of teleconsultation itself is also required, with particular emphasis on understanding how presence develops during single interactions or over a period of time. The experiences of patients and carers within technology-mediated care require further explanation, 
as do the mechanics of interactions. In particular, more work is required using conversation analysis approaches to understand the detailed interactions between nurse, patient and other agents.

From a research perspective then, this study provides a springboard for two broad streams of subsequent work. It prompts questions related to the use of teleconsultation as a modality of care - how it should best be used; how patients perceive it; where the limits lie. More ambitiously, the work opens up the potential for further study of nursing in general. The embryonic theory of nursing presence described here may be applicable generally, providing a framework for understanding the role of nurses across clinical contexts. By reconceptualising nursing presence, the study offers a new perspective on nurses, their role, their place in practice, and the care they provide.

Teleconsultation is an innovative, expanding and exciting approach to the delivery of healthcare. For nurses, it offers the chance to not only do things differently, but to do different things. This study goes some way to explaining how nurses are using teleconsultation to enhance care, but it is only a stopping off point in a longer journey towards understanding how best to use technology for the benefit of patients.

\section{RELEVANCE TO CLINICAL PRACTICE}

The grounded theory described in this paper offers guidance for the future development and delivery of teleconsultation services. It has highlighted some of the benefits and challenges associated with using teleconsultation, and identified how nurses can adapt their practice to exploit the opportunities provided by technology. Nurses will continue to be at the vanguard of teleconsultation development and delivery - this study offers guidance on the impact of video-mediated communication on their professional role. 


\section{References}

Armfield, N.R., Gray, L.C. \& Smith, A.C. (2012) Clinical use of Skype: a review of the evidence base. Journal of Telemedicine and Telecare, 18(3), 125-127.

Audit Scotland (2011) A review of telehealth in Scotland. Edinburgh, Audit Scotland. Available online:

Www.audit-scotland.gov.uk/docs/health/2011/nr_111013_telehealth.pdf [Accessed $22 / 03 / 2015]$.

Barrett, D., Thorpe, J. \& Goodwin, N. (2015) Examining perspectives on telecare: factors influencing adoption, implementation, and usage. Smart Homecare Technology and TeleHealth 3, 1-8. Available online:

http://www.dovepress.com/examining-perspectives-on-telecare-factors-influencing-adoptionimplem-peer-reviewed-article-SHTT [Accessed 05/01/16].

Benner, P. (1984) From novice to expert: Excellence and power in clinical practice. Menlo Park: Addison-Wesley.

Bohannon, L.S., Herbert, A.M., Pelz, J.B. \& Rantanen, E.M. (2013) Eye contact and videomediated communication: A review. Displays, 34(2), 177-185.

Boychuk Duchscher, J.E. \& Morgan, D. (2004) Grounded Theory: reflections on the emergence vs. forcing debate. Journal of Advanced Nursing, 48(6), 605-612.

Caris-Verhallen, W.M.C.M., Kerkstra, A. \& Bensing, J.M. (1999) Non-verbal behaviour in nurse-elderly patient communication. Journal of Advanced Nursing, 29(4), 808-818.

Chang, S.O. (2001) The conceptual structure of physical touch in caring. Journal of Advanced Nursing, 33(6), 820-827.

Charmaz, K. (2000) Grounded Theory: Objectivist and constructivist methods. In Denzen, N.K. \& Lincoln, Y.S. (eds) Handbook of qualitative research. $2^{\text {nd }}$ edition. Thousand Oaks: Sage, 509-535. 
Charmaz, K. (2006) Constructing grounded theory: A practical guide through qualitative analysis. Los Angeles: Sage.

Coakley, A. \& Duffy, M. (2010) The effect of therapeutic touch on postoperative patients. Journal of Holistic Nursing, 28(3), 193-200.

Cruikshank, J. \& Paxman, J. (2013) Yorkshire and the Humber Telehealth Hub: Project Evaluation. Available online:

http://www.2020health.org/2020health/Publications/Publications-2013/YorkshireTelehealth.html [Accessed 20/02/2015].

Demaerschalk, B., Raman, R., Meyer, B. (2012) Efficacy of telemedicine for stroke: Pooled analysis of the Stroke Team Remote Evaluation Using a Digital Observation Camera (STRokE DOC) and STRokE DOC Arizona telestroke trials. Telemedicine and eHealth, 18(3), 230-237.

Doona, M.E., Chase, S.K. \& Haggerty, L.A. (1999) Nursing presence: As real as a Milky Way bar. Journal of Holistic Nursing, 17, 54-70.

Draucker, C., Martsolf, D., Ross, R. \& Rusk, T. (2007) Theoretical sampling and category development in grounded theory. Qualitative Health Research, 17(8), 1137-1148.

Easter, A. (2000) Construct analysis of four modes of being present. Journal of Holistic Nursing, 18(4), 362-377.

Egan, T.M. (2002) Grounded theory research and theory building. Advances in Developing Human Resources, 4(3), 277-295.

Esterle, L. \& Mathieu-Fritz, A. (2013) Teleconsultation in geriatrics: Impact on professional practice. International Journal of Medical Informatics, 82, 684-695.

Ferguson, J. (2006) How to do a telemedical consultation. Journal of Telemedicine and Telecare, 12(5), 220-227. 
Finfgeld-Connett, D. (2008) Qualitative comparison and synthesis of nursing presence and caring. International Journal of Nursing Terminologies and Classifications, 19(3), 111-119.

Freiburger, G., Holcomb, M. \& Piper, D. (2007) The STARPAHC collection: Part of an archive of the history of telemedicine. Journal of Telemedicine and Telecare, 13, 221-223.

Goran, S.F. (2010) A second set of eyes: An introduction to Tele-ICU. Critical Care Nurse, $30(4), 46-55$.

Gorawara-Bhata, R. \& Cook, M.A. (2011) Eye contact in patient-centered communication. Patient Education and Counselling, 82(3), 442-447

Graneheim, U.H., Lundman B (2004) Qualitative content analysis in nursing research: concepts, procedures and measures to achieve trustworthiness. Nurse Education Today, 24(2), $105-112$

Hervieu-Begue, M., Jacquin, A., Osseby, G.V., Quantin, C., Hérail, E., Minier, D., Ricolfi,,F., Honnart, D., Freysz, M., Barrondeau-Leuret, A., Béjot, Y., Mayol, B., Cottin, Y., Lerhun, B., Cavalier, M. \& Giroud, M. (2013) The role of the clinical nurse within a combined stroke and telefibrinolysis network: The G5 pilot study in Burgundy, France. European Research in Telemedicine, 2, 11-15.

Higginbottom, G. (2004) Sampling issues in qualitative research. Nurse Researcher, 12(1), 719.

Jenkins, R.L. \& White, P. (2001) Telehealth advancing nursing practice. Nursing Outlook, 49(2), 100-105.

Karagozoglu, S. \& Kahve, E. (2013) Effects of back massage on chemotherapy-related fatigue and anxiety: Supportive care and therapeutic touch in cancer nursing. Applied Nursing Research, 26(4), 210-217. 
Lempert, L.B. (2007) Asking questions of the data: memo writing in the grounded theory tradition. In Bryant, A. \& Charmaz, K. (eds) The SAGE handbook of grounded theory. Los Angeles: Sage, 245-264.

LeRouge, C., Garfield, M.J. \& Collins, R.W. (2012) Telemedicine: Technology mediated service relationship, or something else? International Journal of Medical Informatics, 81, 622636

Lindgren, L., Lehtipalo, S., Winsö, O., Karlsson, M., Wiklund, U. \& Brulin, C. (2013) Touch massage: a pilot study of a complex intervention. Nursing in Critical Care, 18(6), 269-277.

Low, J.A., Beins, G., Lee, K.K. \& Koh, E. (2013) Last moments of life: Can telemedicine play a role? Palliative and Supportive Care, 11, 353-355.

Mills, J., Bonner, A. \& Francis, K. (2006) The development of constructivist grounded theory. International Journal of Qualitative Methods, 5(1), 25-35.

Nagel, D.A., Pomerleau, S.G. \& Penner, J.L. (2013) Knowing, caring and telehealth technology: "Going the distance" in nursing practice. Journal of Holistic Nursing, 31(2), 104112.

Sävenstedt, S., Zingmark, K., Hydén, L. \& Brulin, C. (2005) Establishing joint attention in remote talks with the elderly about health: A study of nurses' conversation with elderly persons in teleconsultations. Scandinavian Journal of Caring Sciences, 19(4), 317-324.

Schmidt, K.L., Gentry, A., Monin, J.K. \& Courtney, K.L. (2011) Demonstration of facial communication of emotion through telehospice videophone contact. Telemedicine and $e$ Health, 17(5), 399-401.

Shah, M.N., Morris, D., Jones, C.M.C., Gillespie, S.M., Nelson, D.L., McConnochie, K.M. \& Dozier, A. (2013) A qualitative evaluation of a telemedicine-enhanced emergency care program for older adults. Journal of the American Geriatrics Society, 61(4), 571-576. 
Shattell, M. (2004) Nurse-patient interaction: a review of the literature. Journal of Clinical Nursing 13(6), 714-722.

Strauss, A. \& Corbin, J. (1998) Basics of qualitative research: Techniques and procedures for developing grounded theory, $2^{\text {nd }}$ edition. Thousand Oaks: Sage Publications.

Tachakra, S. \& Rajani, R. (2002) Social presence in telemedicine. Journal of Telemedicine and Telecare, 8, 226-230.

Tuxbury, J.S. (2013) The experience of presence among telehealth nurses. The Journal of Nursing Research, 21(3), 155-161.

Warshaw, E.M., Hillman, Y.J., Greer, N.L., Hagel, E.M., MacDonald, R., Rutks, I.R. \& Wilt, T.J. (2011) Teledermatology for diagnosis and management of skin conditions: A systematic review. Journal of the American Academy of Dermatology, 64(4), 759-772.e21.

While, A. \& Dewsbury, G. (2011) Nursing and information and communication technology (ICT): A discussion of trends and future directions. International Journal of Nursing Studies, 48, 1302-1310.

Zyblock, D.M. (2010) Nursing presence in contemporary nursing practice. Nursing Forum, 45(2), 120-124. 